\title{
Democratismo entre atores políticos não estatais
}

Democratism between non-state political actors

\section{Éder Rodrigo Gimenes \\ Ednaldo Aparecido Ribeiro}

\section{Resumo}

A pesquisa objetivou identificar a existência de um hiato entre apoio difuso e específico à democracia entre atores políticos não estatais por meio da mensuração da adesão e de correlatos com o democratismo, por meio de um survey. Os resultados evidenciaram forte apoio abstrato e medidas intermediárias de apoio específico, refletindo um gap, ainda que em menor medida que aquele referente à população brasileira. A análise estatística bivariada e multivariada apontou eficácia política subjetiva, autoposicionamento no espectro ideológico e participação politica não convencional como variáveis mais relevantes à mensuração do apoio ao democratismo entre o segmento de elite não estatal pesquisado.

\section{Palavras-chave}

Cultura Política; Democracia; Elites; Apoio Difuso; Apoio Específico.

\begin{abstract}
The research aimed to identify the existence of the gap between specific and diffuse support for democracy among non-state political actors through the measurement of membership and of correlates with democracy, through the application of a survey. The results showed strong abstract support and intermediate measures of specific support, reflecting a gap, albeit to a lesser extent than that of the Brazilian population. The bivariate and multivariate statistical analysis showed subjective political efficacy and positioning on the ideological spectrum as the most important variables measuring support for democracy among the elite segment of non-state research.
\end{abstract}

\section{Keywords}

Political Culture; Democracy; Elites; Diffuse Support; Specific Support. 


\section{Introdução}

Os processos de consolidação e aprofundamento de democracias têm sido contemporaneamente entendidos como fenômenos multifatoriais. Desta forma, além de variáveis ligadas às instituições políticas e a condicionantes econômicos, um número cada vez maior de cientistas políticos tem voltado sua atenção para os valores e atitudes dos atores políticos que vivem nesses regimes (MOISÉS, 1995; BAQUERO, 2010).

Nos estudos que focalizam essa dimensão subjetiva são particularmente relevantes indicadores relacionados à adesão normativa dos indivíduos à democracia como forma de governo. Todos os surveys conduzidos nacional e internacionalmente trazem em seus questionários perguntas relacionadas a esse tema. No que diz respeito à região latino-americana e, mais especificamente, ao Brasil, os dados coletados pelo Latinobarómetro (2009) podem nos ajudar a compor um quadro do democratismo. Em metade dos países latino-americanos o percentual de cidadãos que considera a democracia como a melhor forma de governo é inferior ou ligeiramente superior à metade do número de entrevistados. Em termos quantitativos, o Brasil ocupa apenas a décima posição dentre os dezoito países analisados.

$\mathrm{Na}$ verdade, assim como outros países submetidos no século passado a regimes autoritários, o Brasil tem vivenciado apenas nas últimas décadas a experiência democrática, de modo que o termo jovem democracia se aplica com propriedade ao atual contexto nacional. A implantação do referido regime após o período militar, ao menos no que tange ao que Lima e Cheibub (1996) denominam primeira transição, já se consolidou, uma vez que tal período se estende da queda do regime autoritário prévio até a instalação do primeiro governo democraticamente eleito, fatos que no Brasil ocorreram ainda na década de 1980.

Ainda segundo tais autores, o problema ocorre após a primeira transição, quando se trata do conteúdo da democracia, ou seja, sua consolidação e seu funcionamento efetivo. A segunda transição seria uma área nebulosa com muitos problemas que dificultam a sua definição, dentre os quais merece destaque as bases para adesão dos atores às regras do jogo político democrático, com oposição entre adesão instrumental com ênfase nas instituições e adesão baseada em princípios e valores.

Diante desse cenário e corroborando com o problema destacado por Lima e Cheibub (1996), autores como Moisés (1995 e 2005) e Ribeiro (2011b) identificaram em suas pesquisas diferentes níveis de adesão ao regime democrático entre os brasileiros, com distinção entre o apoio à democracia em termos abstratos e avaliativos, conforme medidas definidas por Easton (1975). Segundo esse último autor, a adesão ao regime em termos abstratos ou normativos se refere aos valores dos indivíduos acerca do sistema, ao passo que o apoio específico trata da avaliação dos indivíduos quanto ao desempenho de instituições 
e autoridades. Nesse sentido, a discrepância entre os dois níveis encontrada no Brasil vai de encontro àquela identificada também entre os demais países da América Latina (BAQUERO, 2010).

Ainda são incertos os efeitos concretos desse descompasso sobre o sistema político como um todo no médio e longo prazo, mas desde já esse fenômeno merece a atenção da Ciência Política, pois é plausível supor que sucessivas avaliações negativas sobre o funcionamento concreto das instituições e da atuação dos seus operadores não devem impactar positivamente as chances de consolidação e aprofundamento de jovens democracias. Adicionalmente, nos parece plausível supor que esses efeitos, ainda não totalmente compreendidos, podem ser ainda mais relevantes quando desviamos nosso olhar para grupos específicos de cidadãos que ocupam papel de destaque nos processos políticos nacionais e regionais.

O presente trabalho pretende contribuir para a compreensão desse tema ao focalizar um grupo que acreditamos ser possível definir como elite não estatal, composto por dirigentes de organizações não governamentais com atuação no nível municipal. Interessa-nos verificar se entre esses indivíduos destacados na vida política municipal existe tal gap $^{1}$ entre a adesão normativa e o apoio específico à democracia, bem como a identificação de alguns correlatos desses níveis de apoio.

Para tanto, as seções que seguem estão dispostas da seguinte maneira: inicialmente apresentamos breve discussão teórica acerca da relação entre cultura política, democracia e elites, buscando justificar o recorte populacional adotado na investigação; na sequência descrevemos alguns dos aspectos metodológicos da pesquisa; por fim, apresentamos e discutimos os resultados das análises sobre os diferentes níveis de apoio democrático entre essa elite e também dos testes com alguns dos seus possíveis correlatos.

\section{Cultura política, democracia e elites}

A preocupação com a adesão subjetiva dos indivíduos aos regimes políticos não é recente, tendo como obra referencial o pioneiro estudo The Civic Culture [1963], de Almond e Verba (1989), que investigaram a congruência entre variáveis subjetivas e o sistema político de Alemanha, Estados Unidos, Inglaterra, Itália e México. A despeito de todas as críticas, sua tentativa de construção de uma conexão entre variáveis individuais e estruturas políticas estabeleceu um promissor programa de pesquisas que tem envolvido atualmente um número crescente de investigadores das Ciências Sociais.

A partir de múltiplas influências que vão da psicologia social à psicoantropologia, esses pesquisadores definiram o conceito central de sua pesquisa como "[...] political orientations - atittudes toward the political system and its

\footnotetext{
${ }^{1}$ Termo utilizado para representação da discrepância entre as medidas de apoio difuso e específico à democracia (EASTON, 1975; MOISÉS, 1995 e 2005; RIBEIRO, 2011; GIMENES, 2011).
} 
various parts, and attitudes toward the role of the self in the system" (ALMOND e VERBA, 1989, p. 12). Esse padrão supostamente poderia explicar em alguma medida as motivações que estão por trás das ações dos atores sociais no campo da política.

As orientações a que se referiram os autores compreenderiam níveis diferenciados de racionalidade e consciência, podendo ser divididas em três tipos básicos: cognitivas, afetivas e avaliativas. As orientações cognitivas envolveriam os conhecimentos e crenças dos indivíduos sobre os diferentes objetos políticos. As afetivas, por sua vez, se referem aos sentimentos de ligação e envolvimento dos mesmos em relação a esses alvos. Por fim, as avaliativas envolvem os julgamentos e opiniões, que podem ser entendidos como resultado da combinação dos conhecimentos e sentimentos partilhados pelos atores sociais em relação às partes que compõem o sistema político.

Ao nos referirmos aos objetos a que se dirigem tais orientações é preciso destacar que se incluem nessa categoria o sistema político entendido como um todo, suas estruturas de encaminhamento e satisfação de demandas e também a visão que cada um dos indivíduos possui sobre a sua própria atuação como ator político relevante ou não. Na obra de Almond e Verba (1989) essa espécie de autoavaliação recebe a denominação de eficácia política subjetiva.

Tratando especificamente do regime em termos gerais, os autores defendem que o sucesso de um sistema político qualquer depende em grande medida da existência de um grau significativo de congruência entre as instituições concretas e os valores, crenças e atitudes políticas partilhadas pelos cidadãos.

Ribeiro (2011b) salienta que os estudos de cultura política, em virtude das críticas a The Civic Culture, sofreram um período de esquecimento. No entanto, tal situação começou a se alterar na década de 1980, quando autores como Putnam (1996) e Inglehart (1988), que compuseram a segunda geração de autores culturalistas, recuperaram as ideias principais da obra em destaque por meio de pesquisas empíricas de longo alcance geográfico ou histórico.

Para essa geração, em termos subjetivos é fundamental que ocorra a adesão dos indivíduos no plano normativo ao sistema político vigente. No caso das democracias, essa afirmação se torna ainda mais relevante, pois essa forma de governo pressupõe a existência de uma larga margem de legitimidade para funcionar adequadamente.

Uma vez aceito o argumento que afirma a relevância dessa adesão, caberia perguntar se existe uma hierarquia de importância entre as disposições individuais favoráveis ou não entre os distintos grupos que compõem uma mesma nação. Mais especificamente, podemos formular as seguintes questões: a adesão normativa de quem importa? e, a adesão das elites é especialmente relevante?

A maior parte dos estudos recentes que seguem a abordagem culturalista tem se mantido fiel à tradição estabelecida por Almond e Verba no que diz respeito à focalização de unidades nacionais, sem distinguir grupos ou subgrupos. 
Os estudos contemporâneos têm sido realizados a partir de surveys nacionais e terminam por estabelecer um quadro da cultura política de uma sociedade como um todo. Ainda que a importância dessas investigações não possa ser questionada, nos parece plausível supor que se os valores dos cidadãos comuns são relevantes, aqueles partilhados pelas elites sejam ainda mais importantes.

Ao discutir os fatores que favorecem o estabelecimento de regimes democráticos, Robert Dahl (1997), em seu já clássico Poliarquia, dedica todo um capítulo à discussão sobre a importância da crença dos ativistas políticos. Em uma frase que sintetiza o conjunto dos seus argumentos sobre o tema, afirma que seria difícil que um regime dessa natureza pudesse vir a existir sem que uma camada politicamente atuante do país em questão acreditasse nos méritos da democracia e rejeitasse fortemente as demais alternativas de caráter autoritário. De maneira inversa, "num regime hegemônico, os líderes, presumivelmente, pelo menos, devem preferir a hegemonia a qualquer alternativa" (DAHL, 1997, p. 129).

Entendendo que pessoas diferentes provocam efeitos distintos em qualquer sistema político, Dahl propõe como importante questão a identificação de quem alimenta quais crenças políticas. Apesar de ressaltar que essa abordagem não implica na desconsideração dos valores difundidos entre o restante da população, aponta que o conjunto dos valores das camadas politicamente mais atuantes e envolvidas com as atividades políticas pode ser um importante fator nos estudos sobre poliarquias. Esses ativistas políticos, diferentemente da maioria das pessoas, teriam sistemas de crenças complexos e ricos, o que poderia ser explicado em grande medida pela associação entre essa sofisticação e os níveis de escolaridade e interesse em política. No que diz respeito à dimensão estritamente cognitiva da cultura política, Dahl é categórico ao afirmar que é plausível supor que o conhecimento sobre os diferentes aspectos da vida política de um país qualquer seja maior entre os membros dessa elite do que entre a população em geral.

Por possuírem esse sistema supostamente mais sofisticado, os ativistas também teriam a maior probabilidade de serem guiados por suas crenças. Quanto mais rudimentares e desorganizadas são as crenças de um indivíduo, menores são as chances de que tais orientações guiem o seu comportamento, ou seja,

\footnotetext{
[...] uma pessoa cujo sistema de crenças contém efetivamente os pontos fundamentais da argumentação de Mill sobre a liberdade, muito provavelmente se oporá a um regime que ameace impor a censura à imprensa ou a supressão de partidos políticos. [...] Mas é muito difícil prever o tipo de regime, movimento ou partido que sofreria oposição ou respaldo de alguém cujo credo político pode ser resumido em "os tempos estão ruins e pessoas como eu estão na pior, neste país (DAHL, 1997, p. 130-131).
}

Além desses fatores que tornam as crenças desse grupo particularmente relevantes, os ativistas desempenham também papel fundamental nos processo de criação e difusão dos elementos que compõem a cultura política de uma 
sociedade. Nos termos de Dahl, os valores e concepções políticas transmitidas por aquelas pessoas que ocupam posição de destaque na sociedade são mais facilmente assimilados pelos cidadãos médios, o que torna as elites importantes personagens não apenas na elaboração, mas também na difusão dos elementos que compõem a cultura política de uma nação ou grupo.

Em síntese, as elites importam e desconsiderar que elas exercem influência no processo político seria, no mínimo, ingênuo. Em consequência, os valores desta elite importam mais do que os da população em geral, pois, querendo ou não, são os seus membros que estão no comando do processo decisório e suas decisões afetam um leque grande de pessoas. Se a cultura política deve ser considerada um importante fator explicativo para os fenômenos políticos contemporâneos, os valores, crenças e atitudes daquelas pessoas que estão mais diretamente envolvidas nos processos políticos possuem uma relevância ainda maior (GRYNSZPAN, 1996; LIMA e CHEIBUB, 1996; PERISSINOTTO et al., 2007; RIBEIRO e BOLOGNESI, 2008).

Além disso, vale salientar que os ativistas políticos e membros da elite apresentam um sistema de crenças e valores diferente daquele que a maioria das pessoas possui, o que implica afirmar que os membros da elite possuem um maior conhecimento sobre a vida política que a maior parte da população em geral (DAHL, 1997; RIBEIRO e BOLOGNESI, 2008).

Diante do exposto, as crenças e ideias de ativistas políticos e de elites apresentam-se como variáveis relevantes a serem consideradas, sobretudo em contextos como o nosso, no qual o sistema político ainda luta para se consolidar.

\section{Metodologia}

Os dados analisados decorrem da pesquisa intitulada "Cultura política e elites não estatais" (GIMENES e RIBEIRO, 2012), que investigou um segmento de elite não estatal composto por dirigentes de Fundações Privadas e Associações Sem Fins Lucrativos (FASFIL). Tais indivíduos são responsáveis pelo desenvolvimento de atividades voltadas as mais diversas finalidades sociais (TONELLA, 2008) e muitos participam de conselhos gestores e, por conseguinte, da proposição, elaboração e implementação de políticas públicas no âmbito municipal (GIMENES, 2011).

Foram considerados como população da pesquisa os dirigentes de entidades sociais legalmente constituídas como FASFIL no município de Maringá (PR) detentoras de algum título de reconhecimento concedido pelo Governo Federal, totalizando 113 indivíduos, dentre os quais foram sorteados aleatoriamente 82 dirigentes, compondo uma amostra representativa com nível de confiança de $95 \%$ e intervalo de confiança de $5 \%$. 
Os dados coletados por meio da aplicação dos questionários foram tabulados com o software PASW Statistics versão 18, por meio do qual foi possível a realização de análise estatística descritiva, bivariada e multivariada ${ }^{2}$.

\section{Apoio à democracia}

Os atores políticos cujos valores são analisados nesta pesquisa compõem uma elite não estatal majoritariamente masculina, de idade superior a 40 anos, com alta escolaridade, brancos, religiosos, casados, com filhos, com empregos com altos rendimentos em empresas privadas e de classe média. Tais indivíduos apresentaram tendência a posicionamento de direita no espectro ideológico, alto interesse por política e entendimento mediano quanto à sua eficácia política subjetiva.

Sobre tais dados cabe destacar que o grupo apresenta configuração demográfica diferenciada da população municipal, uma vez que esta é predominantemente feminina, com concentração superior a $60 \%$ da população em faixas etárias inferiores a 40 anos e com rendimentos mensais em torno de três salários mínimos.

Sobre o vínculo empregatício, destaque-se que 53,2\% trabalham em empresas privadas ou indústrias, ao passo que $36,4 \%$ trabalham em organizações privadas não-lucrativas e apenas $10,4 \%$ trabalham para o governo ou instituições públicas. Destacamos que mais de um terço dos dirigentes são remunerados pelas entidades em que atuam, mas $63,6 \%$ atuam de maneira voluntária na gestão de tais instituições.

Em termos de engajamento nas FASFIL, a aplicação dos questionários permitiu inferir que o tempo médio de atuação dos entrevistados nas entidades é de 15 anos. No entanto, existe um outlier referente a um dirigente que se encontra evolvido com a instituição há 45 anos. Além dessa informação, cabe ressaltar que $37 \%$ declararam participar de mais entidades além daquelas das quais são dirigentes, o que indica expressivo engajamento institucional.

Passando as questões que nos interessam mais diretamente nesse trabalho, inicialmente apresentamos alguns resultados relativos à dimensão difusa do apoio, tal como definida por Easton (1975).

Em questão que solicitava aos entrevistados que indicassem dentre três afirmações sobre regimes políticos qual mais se aproximaria de seu pensamento, a grande maioria dos dirigentes $(84,1 \%)$ optou pela frase "A democracia é sempre melhor do que qualquer outra forma de governo", enquanto $12,2 \%$ escolheram a opção "Em certas situações, é melhor uma ditadura do que um regime democrático" e apenas 3,7\% optaram pela afirmação "Tanto faz se o governo é uma democracia ou uma ditadura", indicativo, em alta medida, de adesão à democracia em termos abstratos.

Os dirigentes foram ainda questionados quanto à medida que consideram

\footnotetext{
${ }^{2}$ Informações técnicas sobre as variáveis podem ser solicitadas, por e-mail, aos autores.
} 
importante viver em um país governado de maneira democrática, por meio de uma escala de um a dez, em que um significa "nada importante" e dez significa "totalmente importante". Nenhum dirigente apontou os quatro primeiros pontos da escala e apenas um selecionou o valor cinco $(1,2 \%)$, de modo que a expressiva maioria $(98,8 \%)$ se concentrou na metade à direita da escala, com 53,7\% dos casos no ponto máximo. A média encontrada para a variável foi de 9,01 , com desvio-padrão de 1,27, o que permite inferir que os dirigentes entendem em medida expressiva que é importante viver sob um regime democrático e mesmo aqueles indivíduos que se encontram a até três desvios-padrão da média se localizam na metade superior da escala.

Uma vez que é possível inferir que a democracia é considerada a melhor forma de governo pelos dirigentes de FASFIL entrevistados e também que tais indivíduos consideram muito importante viver em um país governado de maneira democrática, pode-se buscar entender a que tipo de democracia tais dirigentes aderem.

Para tanto utilizamos variáveis geradas por um conjunto de questões que interrogavam os entrevistados sobre a relevância de algumas características para a constituição de um regime democrático. Para cada uma das características listadas (Tabela 1) os indivíduos deveriam se posicionar em uma escala de dez pontos, na qual um equivale a "não é uma característica fundamental da democracia" e dez a "é uma característica fundamental da democracia". Os resultados obtidos com esse procedimento seguem abaixo.

Tabela 1 - Características fundamentais da democracia

\begin{tabular}{c|c|c}
\hline Característica & Média & Desvio-padrão \\
\hline O povo escolhe seus líderes em eleições livres. & 8,84 & 1,69 \\
\hline As mulheres têm os mesmos direitos que os \\
homens. & 8,59 & 2,37 \\
\hline Direitos do cidadão protegem a liberdade do povo \\
contra a opressão. & 8,39 & 1,78 \\
\hline O povo pode mudar as leis pelo voto. & 8,35 & 2,37 \\
\hline Os criminosos são severamente punidos. & 6,39 & 3,05 \\
\hline $\begin{array}{c}\text { As Forças Armadas assumem o governo quando } \\
\text { ele for incompetente. }\end{array}$ & 4,24 & 3 \\
\hline O governo cobra impostos dos ricos e dá dinheiro \\
aos pobres.
\end{tabular}

Fonte: Gimenes e Ribeiro (2012).

Os valores apresentados na Tabela 1 demonstram que os dirigentes de FASFIL acreditam em grande medida que a escolha de líderes em eleições livres, 
direitos iguais para mulheres e homens, proteção da liberdade do povo contra a opressão por meio de direitos e possibilidade de mudança das leis pelo voto são características fundamentais da democracia, tanto que as quatro primeiras afirmações apresentaram médias superiores ao ponto oito da escala, sendo que para todas o ponto máximo foi o mais citado pelos entrevistados, com percentuais de concentração de casos da metade à direita da escala entre 84,8\% e 92,5\%.

Já a afirmação "Os criminosos são severamente punidos" foi considerada pela amostra dos dirigentes como uma característica fundamental da democracia de maneira intermediária, uma vez que concentrou 62,5\% dos casos da metade à direita da escala. Finalizando a bateria relacionada às características fundamentais da democracia, as afirmações "As Forças Armadas assumem o governo quando ele for incompetente" e "O governo cobra impostos dos ricos e dá dinheiro aos pobres" foram consideradas de forma fraca à mediana, como características fundamentais do referido sistema pela maior parte dos entrevistados.

Para além dessa adesão geral à democracia, nos interessava também identificar com mais detalhe a posição dessa elite em relação à dimensão participativa dessa forma de governo, sobretudo focalizando algumas inovações institucionais relevantes no cenário nacional recente. Desta forma, os entrevistados foram questionados, tomando por base a mesma escala utilizada para a bateria de questões anteriores, quanto à medida que concordam com algumas formas de participação política num regime democrático. $\mathrm{O}$ resultado segue exposto na Tabela 2.

Tabela 2 - Participação política

\begin{tabular}{|c|c|c|}
\hline Característica & Média & Desvio-padrão \\
\hline $\begin{array}{l}\text { Só há democracia se houver participação pelo } \\
\text { voto. }\end{array}$ & 8,64 & 2,02 \\
\hline $\begin{array}{l}\text { Só há democracia se houver participação direta } \\
\text { em todas as decisões políticas. }\end{array}$ & 7,17 & 2,49 \\
\hline $\begin{array}{c}\text { Só há democracia se houver participação por } \\
\text { plebiscitos. }\end{array}$ & 6,95 & 2,61 \\
\hline $\begin{array}{c}\text { Só há democracia se houver participação por } \\
\text { orçamentos participativos. }\end{array}$ & 6,73 & 2,24 \\
\hline $\begin{array}{l}\text { Só há democracia se houver participação por } \\
\text { conselhos gestores. }\end{array}$ & 6,14 & 2,41 \\
\hline
\end{tabular}

Fonte: Gimenes e Ribeiro (2012).

A afirmação de que "Só há democracia se houver participação pelo voto" obteve a maior média e mediana dez, indicando que a maior parte dos casos se concentrou no ponto máximo da escala $(51,3 \%)$, além de $90 \%$ dos casos na metade à direita da escala, o que revela alta adesão entre a elite não estatal maringaense à democracia representativa.

As demais formas de participação apresentadas na bateria, mais 
relacionadas a formas de participação mais diretas e não representativas, obtiveram médias menores, porém todas também localizadas na metade à direita da escala, também indicando maior propensão à concordância com a ideia de que só há democracia se houver participação direta em todas as decisões políticas e ainda por plebiscitos, orçamentos participativos e conselhos gestores.

Os desvios-padrão apresentados na Tabela 2, apesar de próximos, possuem diferentes características, cabendo destacar que indivíduos que se encontram a um desvio-padrão da média a menor para as três últimas afirmações encontram-se na metade à esquerda da escala utilizada para coleta de dados, o que significa que tendem a discordar das afirmações em questão.

Essa bateria de afirmações permite inferir que entre os dirigentes de FASFIL entrevistados prevalece o modelo de democracia representativa, uma vez que apesar de concordarem com as demais formas de participação, concernentes ao modelo participativo de democracia, a afirmação "Só há democracia se houver participação pelo voto" obteve média e maior concentração de casos na metade à direita da escala superior às demais afirmações.

Diante de tal constatação cabe destacar que, em discussão sobre a participação dos atores civis em instrumentos democráticos, Dombrowski e Parmigiani (2009) e Dombrowski (2010) afirmam que o engajamento em conselhos gestores e orçamentos participativos é prejudicado principalmente por três razões: os custos imputados para a participação, a linguagem técnica utilizada em tais espaços democráticos e a dificuldade de implementação das decisões deliberadas em tais reuniões.

Passando às medidas de apoio específico, inicialmente os dirigentes foram questionados sobre a forma como o Brasil está sendo governado, tendo como referência uma escala de um a dez, na qual um significa "nada democrático" e dez significa "totalmente democrático". Como resultado, verificamos que nenhum dirigente selecionou os pontos extremos da escala. Dentre as respostas, a maior parte se concentrou na metade mais próxima ao ponto máximo, indicando uma forte tendência à concordância com a ideia de que o Brasil está sendo governando de maneira democrática atualmente $(73,2 \%)$, com média de 6,33 .

Ainda sobre esse mesmo tema, solicitamos aos entrevistados que avaliassem o sistema político em três diferentes momentos: 1) há dez anos atrás; 2) atualmente; 3) daqui a dez anos. Para tais avaliações foi utilizada uma escala em que um significa "muito ruim" e dez significa "muito bom", conforme disposto na Tabela 3. 
Tabela 3 - Avaliação do sistema político

\begin{tabular}{c|c|c}
\hline Período & Média & Desvio-padrão \\
\hline Há dez anos atrás & 4,28 & 1,87 \\
\hline Atual & 4,32 & 1,85 \\
\hline Expectativa para daqui a dez anos & 6,61 & 1,9 \\
\hline
\end{tabular}

Fonte: Gimenes e Ribeiro (2012).

Em se tratando da avaliação do sistema político há dez anos e atual, a maior parte dos casos se concentrou na metade esquerda da escala, que congrega $78 \%$ dos casos para ambas as variáveis e médias praticamente iguais, evidenciando o entendimento dos dirigentes entrevistados quanto à lenta melhoria no sistema político brasileiro na última década, uma vez que a média sofreu um pequeno aumento.

Quanto à expectativa dos entrevistados em relação ao sistema político daqui a dez anos, a maior parte das respostas se concentrou entre os pontos seis e dez da escala (74,4\% dos casos), indicando otimismo quanto ao futuro da democracia na próxima década.

Ainda que não existam evidências empíricas consistentes sobre os efeitos da desconfiança institucional sobre a legitimidade democrática, julgamos plausível supor que o persistente desencanto com as principais instituições democráticas seja prejudicial à estabilidade do regime em países onde a democracia se encontra menos fortalecida por conta do breve período de sua implantação e que, por conseguinte, possuem reservatórios de legitimidade menores. Desta forma, níveis elevados de desconfiança se constituiriam em indicadores de risco à democracia (MOISÉS, 2005; SELIGSON, BOOTH e GÓMEZ, 2006; MOISÉS e CARNEIRO, 2008; RIBEIRO, 2010).

Moisés (2005), Moisés e Carneiro (2008) e Ribeiro (2009; 2010 e 2011a) defendem que a análise dos índices de confiança em países nos quais os regimes democráticos são recentes não pode se dar de maneira semelhante àqueles onde tal regime encontra-se consolidado. Nesse sentido, a desconfiança política é aqui interpretada como uma manifestação crítica em relação às instituições democráticas, capaz de potencializar o aprofundamento democrático por meio do aumento da participação convencional e não convencional.

Em nossa pesquisa os dirigentes foram questionados quanto à sua confiança em algumas instituições tomando por base uma escala de confiança com as seguintes opções: não confia, confia pouco, confia em parte e confia totalmente. O resultado é exposto na Tabela 4. 
Tabela 4 - Confiança em instituições democráticas (\%)

\begin{tabular}{c|c|c|c|c}
\hline Instituição & $\begin{array}{c}\text { Não } \\
\text { confia }\end{array}$ & $\begin{array}{c}\text { Confia } \\
\text { pouco }\end{array}$ & $\begin{array}{c}\text { Confia } \\
\text { em parte }\end{array}$ & $\begin{array}{c}\text { Confia } \\
\text { totalmente }\end{array}$ \\
\hline Sindicatos & 13,4 & 29,3 & 54,9 & 2,4 \\
\hline Sistema Judiciário & 7,3 & 20,7 & 68,3 & 3,7 \\
\hline Governo Federal & 6,1 & 32,9 & 62,2 & 4,9 \\
\hline Governo Estadual & 9,8 & 29,2 & 57,3 & 3,7 \\
\hline Governo Municipal & 4,9 & 31,7 & 59,7 & 3,7 \\
\hline Congresso Nacional (Câmara e Senado) & 13,4 & 52,4 & 31,8 & 2,4 \\
\hline Assembleia Legislativa Estadual & 15,9 & 48,8 & 34,1 & 1,2 \\
\hline Câmara de Vereadores & 18,3 & 43,9 & 36,6 & 1,2 \\
\hline Partidos Políticos & 15,9 & 52,4 & 30,5 & 1,2 \\
\hline Serviços Públicos & 2,4 & 28,1 & 68,3 & 1,2 \\
\hline
\end{tabular}

Fonte: Gimenes e Ribeiro (2012).

A tabela acima evidencia que a maior parte dos entrevistados confia em parte nos sindicatos, no Sistema Judiciário, no Poder Executivo e nos serviços públicos. Da mesma forma, confia pouco no Poder Legislativo e nos partidos políticos. Além disso, verifica-se que o Congresso Nacional, a Assembleia Legislativa Estadual, a Câmara de Vereadores e os partidos políticos concentram percentuais superiores a $60 \%$ das respostas entre as opções não confia e confia pouco. Por fim, cabe destacar que nenhuma instituição atingiu o percentual de $10 \%$ de casos de confiança total dentre os dirigentes de FASFIL. Tais percentuais apontam para a desconfiança (ou pouca confiança) por parte da elite não estatal maringaense das principais instituições componentes do sistema democrático.

Em se tratando do apoio específico da elite não estatal à democracia podemos concluir que tal grupo entende em medida moderada que o Brasil é governado de maneira democrática atualmente e, apesar de reconhecerem uma melhoria quase insignificante no sistema político na última década, têm expectativa de melhora considerável nos próximos dez anos. Além disso, os dirigentes demonstraram confiar pouco nas instituições-chave do regime democrático, ainda que confiem mais que a população brasileira em geral no Congresso Nacional, nos Governos Federal e Municipal e no Sistema Judiciário (GIMENES, 2011).

Considerando que as medidas quantitativas de adesão normativa resultaram em valores elevados e que as medidas avaliativas de apoio à democracia retornaram valores moderados, é possível inferir que existe uma discrepância. Desta forma, apesar de serem mais participativos que a população brasileira em geral, tanto pelos cargos de gestores de FASFIL quanto pela posição ocupada nos conselhos gestores municipais, tais indivíduos manifestaram em suas 
opiniões uma diferenciação entre apoio abstrato e avaliativo que constitui um gap, a exemplo daquele mencionado pelas pesquisas anteriormente destacadas.

Para fins de parametrização, Gimenes (2011) comparou os resultados encontrados com aqueles decorrentes de pesquisas realizadas em nível local, regional e nacional ${ }^{3}$, cuja análise permitiu inferir que o segmento de elite não estatal maringaense apresentou menor gap entre as medidas de apoio difuso e específico que as amostras apresentadas nas demais pesquisas, de modo que os dirigentes das FASFIL demonstraram adesão mais robusta ao sistema democrático que a população nacional e da Região Metropolitana de Maringá (RMM) e os segmentos de elite nacional e local utilizados para comparação ${ }^{4}$.

\section{Correlatos do apoio à democracia}

Após analisarmos os diferentes níveis de apoio à democracia entre a elite investigada, buscamos também identificar alguns dos seus correlatos. Para tanto, concentramos nossa atenção no nível difuso da adesão, configurando o que podemos chamar de democratismo.

Com o objetivo de criar um único indicador, optamos por reunir diferentes variáveis em um índice somatório através do qual fosse possível dispor os entrevistados em uma escala numérica relativamente ampla que representasse a intensidade de sua adesão normativa. A primeira delas solicitava aos entrevistados que indicassem dentre três afirmações sobre regimes políticos qual mais se aproximaria de seu pensamento: "a democracia é sempre melhor do que qualquer outra forma de governo"; "em certas situações, é melhor uma ditadura do que um regime democrático" ou "tanto faz se o governo é uma democracia ou uma ditadura". Recodificamos a variável de forma que a primeira opção representasse o valor um e as demais zero. As outras três variáveis foram obtidas por meio de solicitações para que os indivíduos avaliassem três situações políticas distintas: 1) o governo de um líder forte; 2) um regime militar; 3) um governo democrático. Todas elas possuíam como alternativas as opções péssimo, ruim, bom e ótimo, mas no caso das duas primeiras a escala foi invertida para que avaliações positivas dessas situações contrárias à democracia equivalessem a pontuações reduzidas na

\footnotetext{
${ }^{3}$ No nível local, foram abordados dois estudos sobre cultura política desenvolvidos por Tonella (2008 e 2011) na RMM, sendo o primeiro com dirigentes de entidades que atuam na área de assistência social e o segundo com uma amostra da população em geral. No nível regional, foram tomados como referência comparativa os dados apresentados por Perissinotto et al. (2007) acerca de três segmentos específicos da elite paranaense (administrativa, partidária e política) no período compreendido entre os anos de 1995 e 2002. Por fim, em termos nacionais, são expostos resultados de surveys realizados pelos institutos internacionais World Values Survey - WVS (2006), Latinobarómetro (2007) e Latin American Public Opinion Project - LAPOP (2010), do Estudo Eleitoral Brasileiro - ESEB (2002) e da pesquisa de Lima e Cheibub (1996) sobre quatro segmentos de elites políticas e sociais no Brasil (políticos, administradores públicos, empresários e líderes sindicais).

4 A análise detalhada dos resultados em perspectiva comparada está disponível em Gimenes (2011).
} 
escala. Com essas recodificações conduzimos um teste de consistência interna que resultou em um coeficiente Alpha de Cronbach de 0,57, indicando a possibilidade de redução das medidas a uma escala integrada. O procedimento somatório resultou em um índice que vai de zero a dez e o teste de Skewness com valor de 0,96 indica distribuição aproximadamente normal (BOHRNSTEDT e KNOKE, 1989).

Como possíveis correlatos de disposições pró-democracia, inicialmente foram selecionadas variáveis que dizem respeito ao envolvimento político dos dirigentes em organizações participativas formais e também em redes de associações ligadas ao segmento das FASFIL. Como medida quantitativa da participação em entidades sociais, incluímos na análise o tempo de participação na FASFIL como um indicador da consistência do seu vínculo associativo. Já com relação a informações categóricas, realizamos testes com três diferentes variáveis, quais sejam: a primeira diz respeito à atuação dos entrevistados em conselhos gestores do município; a segunda é uma medida do envolvimento dos mesmos em outras organizações semelhantes às que dirigem; e a terceira trata do vínculo empregatício do indivíduo na entidade que dirige, em contrapartida com aqueles que possuem vínculos formais e remunerados em empresas privadas ou são funcionários públicos.

Acreditamos que esse conjunto de variáveis torne possível testar a hipótese de que o envolvimento extensivo e intensivo em espaços e instituições políticas diversas possibilita a incorporação de valores pró-democracia, configurando assim uma dimensão pedagógica da participação.

No campo das atitudes e valores, julgamos pertinente introduzir na análise o nível de interesse por política entre os indivíduos, variável normalmente associada à chamada cultura cívica e potencialmente favorável ao democratismo (MOISÉS, 1992; ALBUQUERQUE, 1992; BALBACHEVSKY, 1992; DAHL, 1997; RIBEIRO, 2011b).

Entendida nos termos de Almond e Verba (1989), a variável eficácia política subjetiva também foi considerada como relevante nessa investigação dos correlatos. Neste caso, nos interessa verificar se os dotados de maior eficácia são também os que manifestam níveis mais elevados de democratismo (INGLEHART, 1988; PUTNAM, 1996; RIBEIRO, 2011b).

Como alguns estudiosos têm identificado recentemente a existência de uma relação significativa entre posicionamento ideológico e variáveis atitudinais, também selecionamos a variável autoidentificação ideológica (ALBUQUERQUE, 1992; REIS e CASTRO, 1992; BALBACHEVSKY, 1992) e foi identificada como variável com maior número de associações estatisticamente aceitáveis com relação à medida normativa de adesão ao regime democrático (GIMENES, 2011).

Além dessas variáveis, também testamos o relacionamento entre a adesão ao regime democrático e a satisfação com a situação financeira familiar dos indivíduos, buscando identificar associação entre a avaliação positiva da realidade 
econômica dos dirigentes e sua satisfação com a democracia.

Por fim, objetivamos testar o relacionamento entre a participação política não convencional, nos termos de Della Porta (2003) e Norris (2007), e o democratismo, partindo da hipótese de que indivíduos que se engajam em diferentes modalidades contestatórias seriam mais propensos ao apoio ao regime. Para tanto, construímos um índice de participação política não convencional ${ }^{5}$, o qual abrangeu o engajamento por meio de abaixo-assinados, boicotes, manifestações, passeatas e greves ${ }^{6}$.

Podemos verificar na Tabela 5 que dentre as variáveis testadas, apenas cinco apresentaram resultados significativos. $\mathrm{O}$ fato de participarem de conselhos, o tempo de participação nas entidades que dirigem, o interesse por política e a satisfação com a situação financeira não parecem estar associados a maior ou menor adesão à democracia.

A primeira associação encontrada foi com a variável sobre o envolvimento em outras entidades distintas daquela que dirige e, de maneira interessante, o coeficiente é negativo, indicando que o democratismo tende a ser menor entre aqueles que possuem mais de um envolvimento. Esse resultado nos surpreende, pois o associativismo tem sido associado pela literatura à disposição democrática mais intensa (RIBEIRO e BORBA, 2011). Não temos nesse momento condições de interpretar essa discrepância, mas esse dado revela a necessidade de confirmação desses efeitos em modelos multivariados que possibilitem a inserção de variáveis de controle.

Com relação ao vínculo empregatício, o relacionamento significativo e positivo nos permite inferir que dirigentes que atuam de maneira remunerada nas entidades sociais que dirigem dispõem de maior propensão ao apoio ao democratismo, corroborando com a discussão teórica acerca da maior intensidade de disposição democrática.

A eficácia política dos dirigentes aparece na sequência, porém com coeficiente positivo, ou seja, quanto melhor essa autoavaliação maior é também o democratismo. Neste ponto a expectativa teórica de que esse sentimento positivo seria acompanhado por maior adesão normativa foi corroborada.

Com o maior coeficiente de correlação encontrado, aparece a autoidentificação ideológica. Aqui novamente o sinal do teste é negativo, indicando que posições mais a direita são acompanhadas de manifestações de menor democratismo.

Por fim, o teste indica que indivíduos que participam de maneira

\footnotetext{
${ }^{5} \mathrm{O}$ teste de consistência interna para o conjunto de variáveis resultou em um coeficiente Alpha de Cronbach de 0,748 , valor que indica a possibilidade de redução das medidas a um escala integrada segundo Bohrnstedt e Knoke (1989).

${ }^{6}$ A análise descritiva das diferentes modalidades de participação não convencional, bem como das formas convencionais, para o segmento de elite não estatal maringaense, encontra-se disponível em Gimenes (2012).
} 
contestatória tendem a um maior apoio à democracia, resultado que aponta para o relacionamento entre a adoção de uma postura crítica por parte de tais indivíduos frente ao regime, combinada com o apoio ao mesmo, o que permite inferir que quanto maior a adesão à democracia, maior também o engajamento em atividades que visem ao questionamento de seu funcionamento, com vistas à sua melhoria.

Tabela 5 - Associações e Correlações com Democratismo

\begin{tabular}{c|c|c|c|c}
\hline Variável & Teste & Sig & Valor & $\mathbf{n}$ \\
\hline Tempo de participação na entidade & Pearson & 0,715 & -.041 & 81 \\
\hline Participação em conselhos gestores & Tau $c$ & 0,909 & $-0,012$ & 82 \\
\hline Participação em outras entidades & Tau $c$ & 0,031 & $-0,254$ & 81 \\
\hline Vínculo empregatício & Tau $c$ & 0,033 & 0,252 & 77 \\
\hline Interesse por política & Tau $c$ & 0,926 & 0,008 & 82 \\
\hline Eficácia política subjetiva & Pearson & 0,02 & 0,258 & 81 \\
\hline Autoidentificação ideológica & Pearson & 0 & $-0,421$ & 80 \\
\hline Satisfação com a situação financeira & Pearson & 0,499 & 0,076 & 81 \\
\hline Participação política não convencional & Pearson & 0,009 & 0,287 & 82 \\
\hline
\end{tabular}

Fonte: Gimenes e Ribeiro (2012).

Para avaliar a consistência desses resultados, construímos modelos multivariados contendo as variáveis cujos testes foram significantes como preditoras do democratismo e adicionamos as seguintes variáveis sóciodemográficas de controle: sexo, idade, escolaridade e renda familiar.

A Tabela 6 mostra que depois dos controles inseridos, os efeitos da participação em outras entidades e do vínculo empregatício deixaram de ser relevantes entre a população envolvida na pesquisa. O mesmo não ocorre com as outras três variáveis, pois os seus efeitos foram confirmados de maneira satisfatória.

Tabela 6 - Efeitos sobre o Índice de Democratismo

\begin{tabular}{c|c|c|c}
\hline Correlatos & B & Erro padrão & Sig. \\
\hline Participação em outras entidades & $-0,511$ & 0,361 & 0,162 \\
\hline Vínculo empregatício & 0,661 & 0,397 & 0,101 \\
\hline Eficácia política subjetiva & 0,172 & 0,073 & 0,021 \\
\hline Autoidentificação ideológica & $-0,371$ & 0,092 & 0,000 \\
\hline Participação política não convencional & 0,265 & 0,111 & 0,019 \\
\hline
\end{tabular}

Nota: r-quadrados 0,$023 ; 0,059 ; 0,066 ; 0,187$ e 0,068 .

Fonte: Gimenes e Ribeiro (2012).

A eficácia política subjetiva se mostrou preditora relevante com efeito 
positivo, ou seja, elevações nessa medida de autoavaliação produzem incremento na escala de democratismo. Nesse sentido, é possível inferir que dirigentes que entendem em maior medida que possuem capacidade de influenciar o cenário político são também aqueles que apresentam maior adesão ao democratismo, conforme entendimento de Almond e Verba (1989), Inglehart (1988), Putnam (1996) e Ribeiro (2011b). Tal situação se justifica pelo fato de que em tal regime político existe uma maior possibilidade de interferência e atuação por parte de atores políticos não estatais na condução do Estado, como é o caso das atividades desenvolvidas por tais indivíduos na esfera social.

Todavia, merece destaque também o impacto da autoidentificação ideológica, apesar de negativo. Neste caso, quanto mais à direita da escala que representa o espectro ideológico, menor o democratismo entre os dirigentes das FASFIL. Tal resultado é indicativo de que os indivíduos com posicionamento ideológico mais à esquerda são mais democráticos, o que já foi identificado por Gimenes $(2011)^{7}$ em pesquisa realizada com tais atores, bem como anteriormente por autores como Albuquerque (1992), Reis e Castro (1992), Balbachevsky (1992) e Ribeiro, Carreirão e Borba (2011).

Diante dos resultados das análises bivariadas e multivariadas relacionadas à autoidentificação ideológica, é possível inferir que os resultados encontrados para o segmento de elite não estatal são favoráveis ao sistema democrático e que essa postura está consistentemente relacionada a uma postura ideológica de esquerda e a avaliação positiva sobre a própria capacidade de atuar politicamente.

Por fim, destaque-se a identificação da relevância da participação política não convencional como preditora do democratismo entre os dirigentes de entidades sociais analisados, o que confirma a expectativa teórica de que o posicionamento crítico em relação ao regime, manifestado por meio do engajamento contestatório, pode sinalizar a disposição em lutar pela melhoria da democracia.

\section{Considerações finais}

O presente artigo se justificou pela relevância do estudo da adesão ao democratismo no Brasil, jovem democracia em que tal regime é apoiado por pouco mais da metade da população. Como atestam recentes pesquisas, existe um descompasso entre as medidas de adesão normativa e avaliativa, tanto entre a população brasileira em geral (MOISÉS, 1995 e 2005; RIBEIRO, 2011b), quanto entre segmentos da elite político-administrativa nacional (LIMA e CHEIBUB, 1996; GIMENES, 2011). Sem pretender minimizar a relevância dos valores de massa, nesse trabalho procuramos ressaltar que tal descompasso é mais relevante entre as elites por serem tais indivíduos os condutores dos processos políticos e

\footnotetext{
7 Apenas 2,4\% dos entrevistados não souberam se posicionar no espectro ideológico, o que demonstra que a amostra do segmento de elite não estatal pesquisada goza de relativa clareza no que se refere à diferenciação entre direita e esquerda (GIMENES, 2011).
} 
possuírem um sistema de crenças diferenciado dos cidadãos comuns (GRYNSZPAN, 1996; LIMA e CHEIBUB, 1996; DAHL, 1997; PERISSINOTTO et al., 2007; RIBEIRO, 2011b; BOLOGNESI, 2008).

Diante de tais argumentos, esta pesquisa teve por objetivo verificar entre um grupo definido como elite não estatal a existência de um gap entre a adesão normativa e o apoio específico à democracia, bem como a identificação de alguns correlatos desses níveis de apoio.

Em termos de adesão normativa entre o segmento de elite não estatal, os resultados identificaram forte entendimento de que a democracia é melhor que qualquer outra forma de governo e de que é muito importante viver em um país governado de maneira democrática. Além disso, tais atores consideraram a escolha de líderes em eleições livres, a concessão de direitos iguais a homens e mulheres, a proteção da liberdade do povo contra a opressão, a possibilidade de alteração de leis pelo voto e a punição severa aos criminosos como características fundamentais do regime e demonstraram maior predileção pelo voto como instrumento essencial ao regime democrático, em detrimento de formas mais participativas de atuação.

Quanto à manifestação do apoio específico, foi identificada uma medida moderada de entendimento de que o Brasil está sendo governado de maneira democrática atualmente, ao passo que a avaliação do regime há 10 anos e atualmente indicou valores entre baixos e medianos, com expectativa de melhoria para a próxima década, mas ainda assim em medida moderada. De maneira semelhante, em se tratando da confiança em instituições democráticas, a elite não estatal demonstrou confiar pouco ou em parte nos sindicatos, partidos políticos, serviços públicos e Poderes Judiciário, Executivo e Legislativo.

Tais resultados permitiram inferir que, apesar da cultura política diferenciada da população brasileira em geral por conta de sua participação direta e indireta na formulação e implementação de políticas sociais, os atores componentes da elite não estatal sob análise também manifestaram diferentes magnitudes de apoio abstrato e avaliativo, o que replica, ainda que em medida diferenciada da população nacional, o gap anteriormente destacado.

Com a finalidade de identificar características associadas ao democratismo, foi composto um índice, o qual foi testado com variáveis institucionais e políticas. Foram encontradas associações válidas entre o democratismo e a participação em outras entidades, vínculo empregatício nas instituições, o sentimento de possibilidade de interferência na política, o posicionamento ideológico de esquerda e o engajamento em modalidades contestatórias.

Conhecidas as variáveis associadas ao democratismo, estas foram incluídas, separadamente, em modelos multivariados, controladas por sexo, idade, escolaridade e renda familiar. Assim como os resultados da análise bivariada, os testes de regressão confirmaram a relevância da eficácia política subjetiva, da 
identificação ideológica e do índice de participação política não convencional, desta vez como preditoras do democratismo. Destaque-se que a predição do apoio ao democratismo pela autoidentificação ideológica refere-se ao posicionamento político de esquerda.

No entanto, diferentemente do resultado dos testes de associação, a participação em outras entidades e o vínculo empregatício não foram consideradas preditoras do democratismo pelos testes de regressão, uma vez que a significância dos modelos que tomaram tais variáveis como independentes não atingiram os parâmetros estatísticos exigidos.

Desta forma, é possível inferir que a adesão ao democratismo entre os atores políticos não estatais maringaenses pode ser explicada, em alguma medida, por variáveis relacionadas ao engajamento político de tais indivíduos.

Éder Rodrigo Gimenes é Doutorando em Sociologia Política pela Universidade Federal de Santa Catarina (UFSC). Mestre em Ciências Sociais pela Universidade Estadual de Maringá (UEM). Membro do grupo de pesquisa "Cultura Política, Comportamento e Democracia" (CNPq). E-mail: ergimenes@uem.br

Ednaldo Aparecido Ribeiro é Docente do Programa de Pós-Graduação em Ciências Sociais da Universidade Estadual de Maringá (UEM). Coordenador do grupo de pesquisa "Cultura Política, Comportamento e Democracia" (CNPq). E-mail: ednaldorip@uol.com.br

\section{Referências}

ALBUQUERQUE, José A. Guilhon de. Identidade, oposição e pragmatismo: uma teoria política do voto. Revista Lua Nova, São Paulo, n. 26, p. 53-79, agosto, 1992.

ALMOND, Gabriel; VERBA, Sidney. The civic culture: political attitudes and democracy in five nations. Princeton: Princeton University Press, [1963] 1989.

BOHRNSTEDT, George W., KNOKE, David; MEE, Alisa P. Statistics for social data analysis. Itasca: Peacock, 1988.

BALBACHEVSKY, Elizabeth. Identidade partidária e instituições políticas no Brasil. Revista Lua Nova, São Paulo, n. 26, p. 133-165, agosto, 1992.

BAQUERO, Marcello. A cultura política na agenda da democratização na América Latina. In: (org.). Cultura(s) políticas(s) e democracia no século XXI na América Latina. Porto Alegre: UFRGS, 2010. p. 13-23.

DAHL, R. A. Poliarquia: participação e oposição. São Paulo: USP, 1997.

DELLA PORTA, D. Introdução a Ciência Política. Lisboa: Estampa, 2003. 
DOMBROWSKI, Osmir. "O povo não participa!” Um ensaio sobre o absenteísmo. In: Seminário Nacional/Seminário Internacional Movimentos Sociais, Participação e Democracia, Florianópolis, 2010.

DOMBROWSKI, Osmir; PARMIGIANI, Jacqueline. Não quero saber dos seus conselhos: considerações sobre a nossa democracia participativa. In: Seminário Nacional Estado e Políticas Sociais, 4., Cascavel, 2009.

EASTON, David. A re-assessment of the concept of political support. British Journal of Political Science, Cambridge, v. 5, n. 4, p. 435-457, 1975.

GIMENES, Éder Rodrigo. Cultura política e democracia: apoio difuso e específico entre um segmento da elite não estatal do município de Maringá (PR). 2011. Dissertação (Mestrado em Ciências Sociais) - Programa de PósGraduação em Ciências Sociais, Universidade Estadual de Maringá, Maringá, 2011.

- Engajamento político entre atores não estatais: participação convencional e não convencional em perspectiva comparada. Revista Áskesis, São Carlos, v. 1, n. 2, p. 24-38, jul.-dez. 2012.

GIMENES, Éder Rodrigo; RIBEIRO, Ednaldo A. Banco de dados Cultura política e elites não estatais. São Paulo: Consórcio de Informações Sociais, 2012.

Disponível em: <http://www.nadd.prp.usp.br/cis/DetalheBancoDados.aspx?cod=B466>. Acesso em: 16 ago. 2012.

GRYNSZPAN, Mario. A teoria das elites e sua genealogia consagrada. Revista Brasileira de Informação Bibliográfica em Ciências Sociais, Rio de Janeiro, n. 41, p. 35-83, jan./jun. 1996.

INGLEHART, Ronald. The renaissance of political culture. American Political Science Review, v. 82, n. 4, p. 1203-1230, dez. 1988.

IBGE. Instituto Brasileiro de Geografia e Estatística. Estudo Eleitoral Brasileiro. 2002.

LAPOP. Latin American Public Opinion Project. Banco de dados. 2010.

LATINOBARÓMETRO. Banco de dados. 2007.

LATINOBARÓMETRO. Banco de dados. 2009.

LIMA, Maria Regina S., CHEIBUB, Zairo Borges. Instituições e valores. As dimensões da democracia na visão da elite brasileira. Revista Brasileira de Ciências Sociais, São Paulo, n. 31, p. 83-110, 1996.

MOISÉS, José Álvaro. Democratização e cultura política de massas no Brasil. Revista Lua Nova, São Paulo, n. 26, p. 5-51, ago. 1992.

. Os brasileiros e a democracia: bases sócio-políticas da legitimidade democrática. São Paulo: Ática, 1995.

Cidadania, confiança e instituições democráticas. Revista Lua Nova, São Paulo, n. 65, p. 71-94, maio-ago. 2005.

MOISÉS, José Álvaro, CARNEIRO, Gabriela Piquet. Democracia, desconfiança política e insatisfação com o regime - o caso do Brasil. Revista Opinião 
Pública, Campinas, v. 14, n. 1, p. 1-42, jun. 2008.

NORRIS, Pippa. Democratic Phoenix: political activism worldwide. Cambridge: Cambridge University Press, 2007.

PERISSINOTTO, Renato; CODATO, Adriano; BRAGA, Sérgio; FUKS, Mario (orgs.). Quem governa? Um estudo das elites políticas do Paraná. Curitiba: UFPR, 2007.

PUTNAM, Robert D. Comunidade e democracia: a experiência da Itália Moderna. Rio de Janeiro: FGV, 1996.

REIS, Fábio W.; CASTRO, Mônica Mata M. de. Regiões, classe e ideologia no processo eleitoral brasileiro. Revista Lua Nova, São Paulo, n. 26, p. 81-131, ago. 1992.

RIBEIRO, Ednaldo. A. Confiança política na América Latina: evolução recente determinantes individuais. Revista Política e Sociedade, Florianópolis, v. 8, n. 15, p. 271-297, out. 2009.

. Desconfiança política e legitimidade democrática na América Latina. In: Congresso Latino Americano de Opinião Pública da WAPOR, 3., Queretaro, 2010.

. Cultura política e gênero no Brasil: estudo exploratório sobre as bases da sub-representação feminina. In: BAQUERO, M. (org.). Cultura(s) políticas(s) e democracia no século XXI na América Latina. Porto Alegre: UFRGS, 2011a. p. 195-218.

. Valores pós-materialistas e cultura política no Brasil. Maringá: UEM, $2011 b$.

RIBEIRO, Ednaldo A., BOLOGNESI, Bruno. As elites paranaenses e a democracia: explorando a estrutura dimensional e os determinantes dos seus valores e atitudes políticas. Revista Tomo, São Cristóvão, n. 12, p. 83-110, jan.jun. 2008.

RIBEIRO, Ednaldo A.; BORBA, Julian. Participação e cultura política: rendimentos subjetivos da experiência do Orçamento Participativo. Revista Debates, Porto Alegre, v. 5, n. 1, p. 67-87, jan.-jun. 2011.

RIBEIRO, Ednaldo A.; CARREIRÃO, Yan; BORBA, Julian. Sentimentos partidários e atitudes políticas entre os brasileiros. Revista Opinião Pública, Campinas, v. 17, n. 2, p. 333-368, abr.-maio, 2011.

SELIGSON, Mitchel A.; BOOTH, John A. GÓMEZ, Miguel. Os contornos da cidadania crítica: explorando a legitimidade democrática. Revista Opinião Pública, Campinas, v. 12, n. 1, p. 1-37, abr.-maio, 2006.

TONELLA, Celene. Participação social cultura política e indicadores de associativismo: os dirigentes de entidades sociais. In: ABCP - Encontro da Associação Brasileira de Ciência Política, 6, Campinas, 2008. Campinas: ABCP, 2008.

. Cultura política, dimensões do exercício da cidadania e participação na vida pública em cidades da Região Metropolitana de Maringá - PR. In: 
Congresso Latino Americano de Opinião Pública da WAPOR, 4., Belo Horizonte, 2011.

WVS. World Values Survey. ( 2005-2006). Michigan: World Values Survey, 2006.

Texto recebido em 06 de maio de 2013. Aprovado em 05 de novembro de 2013. 